\title{
MITOLOGÍAS DE AUTOR EN LA ESCRITURA DE LEONARDO PADURA FUENTES. ENTRE HEREDIA Y HEMINGWAY
}

\author{
POR \\ Carmen Perilli \\ UNT-CONICET
}

Las comunidades modulan relatos que representan simbólicamente linajes y mapas, vinculando memorias y territorios. La construcción de las naciones hispanoamericanas, nacidas de la experiencia colonial, forma sus identidades en los combates por la hegemonía de los distintos proyectos.

Desde su surgimiento tardío la narrativa nacional cubana ha sufrido sucesivas reformulaciones, de acuerdo a diferentes intereses. Cuba vive un peculiar y extenso proceso de transición de la alteridad criolla a la identidad nacional. En el transcurso de esta transformación los conceptos patria y nación y sus variantes metafóricas -tierra, sangre y memoria- quedan indisolublemente unidos.

Los relatos nacionales, tramados como narrativas épicas adjudican un papel protagónico a los héroes. En el caso cubano hay una particular relación entre epos y aesthesis, historia y poesía que, desde el inicio de la patria criolla, contribuye a formular una mitología en la que concurren la diáspora, el exilio, el sacrificio, el destierro, la muerte, etc. El afuera adquiere un papel antagónico, en especial los imperios, primero España y luego Estados Unidos. El colonialismo y el neocolonialismo acechan la historia y la cultura de la isla.

En el horizonte del cambio de siglo Cuba se enfrenta al desafío de reconstituir el campo literario e intelectual impactado por las enormes disgregaciones sufridas durante el periodo posrevolucionario, atravesado por afueras y adentros diversos. En esta circunstancia surgen distintas visiones de la nación y se entablan batallas por la memoria y por la tierra.

Entre la isla y la diáspora se extiende un vasto territorio cultural en el que se producen textos muy diversamente relacionados con la nación. Esa literatura creada desde cualquier ciudad del planeta abre un espectro de significaciones en el que se inscriben actitudes cubanas, posnacionales y exteriores. (Rojas, Tumbas 363)

Dentro del relato maestro revolucionario cubano la figura del poeta militante adquiere gran relevancia, encarnado arquetípicamente por José Martí. La idea de patria 
cubana fomentada por el gobierno revolucionario implica una genealogía que, a través de Martí se remonta hasta José María Heredia. La historia cultural y política incorpora un conjunto de escritores latinoamericanos-Gabriel García Márquezy Mario Benedetti, entre otros- y extranjeros como Ernest Hemingway y Graham Green cuyas biografías se solidarizan con la isla y el panteón revolucionario.

En los imaginarios culturales nacionales los autores pueden convertirse en modernos artefactos cultu(r)ales. Entre el personaje y la persona, se exhiben y son exhibidos en ambivalente posición de íconos del sistema estelar nacional y continental. En ese sentido me permito hablar de mito, en el sentido de habla naturalizada, partiendo de la definición de Barthes. La literatura, que construye sus propios mitos, trabaja sobre estas construcciones, se apropia de ellas por medio de la estilización y la parodia. En cualquier caso Julio Premat, refiriéndose a las figuras de autor que habitan el sistema literario habla de "ficción de autor" como identidades inventadas por los escritores, como concepto diferenciado de nombre de autor. Toda escritura, con más o menos fuerza, permite la emergencia de ficciones de autor.

Esas ficciones serían entonces un espacio para resolver conflictos ante la tradición, ante los imperativos de originalidad, ante las expectativas y presiones sociales, pero también un espacio para lidiar con el yo ideal, un espacio para proyectarse en personajes [...]Y que la identidad del escritor es inestable, desplegar esa identidad bajo modos ficticios es, entonces, una modalidad de afirmar procesos identitarios. (28)

El autor se espeja y se dicen desde el otro antecesor con el que establece filiaciones. En esa medida la ficción de autor toma en cuenta los mitos de autor que forman parte del archivo literario. En las novelas de Padura Fuentes se observa el juego entre mitos fundantes como Heredia y Hemingway que dialogan con la autoficción encubierta en las figuras del investigador literario Fernando Terry o del policía y escritor Mario Conde. En el diálogo entre estos espacios se resuelve una identidad de autor cubano, entre el afuera y el adentro.

\section{LOS POETAS Y EL DESTIERRO}

Una lectura de la historia política cubana del siglo xx revela la fuerte presencia de José Martí, en especial en los tres momentos de fundación constitucional: 1901, 1940 y 1976. Simón Bolívary José María Heredia son las grandes figuras paternales reivindicadas por Martí. La paternidad de Heredia, más épica que estética, como señala Rafael Rojas, está más recostada sobre el bios que sobre la grafía. El mito nacionalista martiano se funde con la doctrina de la revolución y preside la cultura oficial posrevolucionaria. ISSN 0034-9631 (Impreso)

vol. LXXIX, Núms. 244-245, Julio-Diciembre 2013, 989-999 ISSN 2154-4794 (Electrónico)
En Cuba, un Estado nacional que acaba de cumplir cien años, la ansiedad del mito ha sido muy intensa. La historia de la poesía cubana, por ejemplo, no es más que la búsqueda y el hallazgo de mitos originarios o fundacionales que identifican a los poetas con su paisaje físico y moral. (Rojas, Tumbas 55)

José María Heredia forma parte de la extensa lista de escritores de la isla que sufren los vaivenes de la complicada relación entre poesía y política. La novela de mi vida de Leonardo Padura Fuentes trabaja la biografía histórica del poeta, confrontando el mito de autor. En el presente de la escritura el crítico e investigador Fernando Terry, enmascara la firma de autor. En los dos casos la historia nacional se dice como historia familiar fraternal. Una familia originariamente entrañable ligada a la revolución y devastada por la historia.

El título de la novela surge de las palabras de José María Heredia en una carta a su tío Ignacio, escritas en el injusto destierro: “¿cuándo acabará la novela de mi vida y comenzará su realidad?". La novela une tres biografías: la autobiografía del poeta, cifrada en unas misteriosas e inhallables memorias; la biografía del hijo José de Jesús Heredia, entregado a la conservación de la memoria del padre y la biografía de Terry, obsesionado por encontrar el manuscrito de las memorias y torturado por su propia historia interrumpida por el exilio.

Heredia, mito de origen de una literatura nacional, ejemplo de poeta cívico, aparece como el fundador de la cubanía literaria. Su vida une destierro, melancolía, enfermedad y duelo. Su historia de sacrificios extremos y su final trágicamente romántico lo convierten en personaje de novela. Padura advierte que la narración autobiográfica se encuentra dentro de los límites de la ficción. En un ensayo posterior titulado José María Heredia: la patria y la vida Padura aduce:

[...] Porque, si no hay dudas de que el primer poeta, o con más propiedad, el primer gran poeta del amplio y poblado parnaso cubano es José María Heredia, no puede menos que intrigarnos el hecho de que un hombre que sólo vivió treinta y cinco años, haya decidido, con tan conocida vehemencia, ser el primer poeta de un país que por entonces ni siquiera existía y en el cual apenas vivió algo más de seis años, la mitad de ellos en su primera infancia. (8)

Es interesante detenernos sobre el uso del término novela. No existen pruebas que ameriten que Heredia, poeta, historiador y dramaturgo, haya sido el autor en $1826 \mathrm{de}$ Xicoténcal, la primera novela histórica mexicana, aunque su nombre haya quedado ligado a ella. A pesar de haber traducido la obra de Walter Scott tiene una visión crítica de la novela histórica. En el "Ensayo sobre la novela" asevera que la novela histórica manipula "[...] el atractivo que tiene el pasado para la imaginación humana [...]", la califica de superficial y la acusa de emplear con falsedad los recuerdos de la historia, ISSN 0034-9631 (Impreso) ISSN 2154-4794 (Electrónico) 
desatendiendo las lecciones del pasado. Sin embargo, el texto que persigue Terry, y que nosotros leemos, se trama como novela. Cifra la novela familiar de Heredia, remite a la familia biológica sino a su familia literaria.

En el juego entre el pasado y el presente Padura Fuentes coloca a la familia como determinante del mundo cultural cubano. En el círculo fraterno de Heredia están Félix Varela, Domingo del Monte, José Luz y Caballero y José Saco. ${ }^{1}$ Ese espacio se quiebra debido a diferencias irreconciliables entre el patriotismo republicano moderno representado por Varela y Heredia y el criollismo patricio de los demás, ligados a la economía esclavista de la plantación.

El fundador de la crítica y la historiografía literaria cubana, Domingo del Monte, protector del esclavo Juan Francisco Manzano y creador de la Academia Cubana de Literatura se convierte en la figura antagónica. ${ }^{2}$ Las Memorias de Heredia es el libro escondido de la historiografía literaria cubana. En cambio Espejo de Paciencia de Silvestre de Balboa es el libro falso con el que la clase patricia inicia una mentirosa genealogía literaria en la colonia.

Leonardo Padura aprovecha la controvertida historia del poema de Balboa para denunciar el carácter ficticio de toda historia literaria. El monumento cultural, supuesta invención de José María Echevarría y Domingo del Monte, niega la modernidad liberal. En el texto el heroísmo y la santidad recaen sobre la Iglesia y el Ejército, el Obispo y el Capitán. Heredia señala “[...] Ahora teníamos a nuestras espaldas [... la invención] de una historia épica, cristiana y remota [...]" (337) ${ }^{3}$

Durante sus años cubanos Heredia participa de la juventud ilustrada y se une a la Logia de los Caballeros Racionales. Sus acciones independentistas y antiesclavistas le valen el destierro. Sus ideales patrióticos son proto-nacionalistas, en parte debido a su

\footnotetext{
"Algunos intelectuales criollos como Félix Varela y José María Heredia, que eran partidarios de 1 independencia, reproducían el concepto nación en los años 20. Otros vinculados a las corrientes reformistas como José Antonio Saco; Domingo del Monte y José de la Luz Caballero preferían hablar de nacionalidad" (Rojas, Motivos 42)

Padura trabaja con los debates sobre las genealogías de la literatura cubana. La discusión del papel de patricios como Saco, Luz y Del Monte tiene una larga tradición ya que eran enemigos del abolicionismo y ultraconservadores.

Espejo de Paciencia lleva por subtítulo "Donde se cuenta la prisión que el capitán Gilberto Girón hizo de

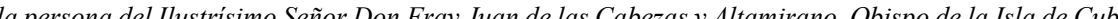

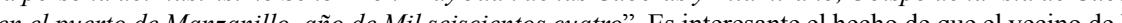
ve

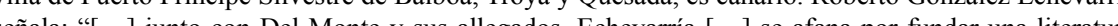
señala: " $[\ldots]$ junto con Del Monte y sus allegados, Echevarria $[\ldots]$ se afana por fundar una literatura nacional, concebida según la ideología romántica que los anima y como parte de un proyecto más amplio de sentar las bases para un concepto de la nacionalidad. Lengua, literatura, historia y naturaleza son los elementos básicos para esa fundación [...]" (577).
}

Revista Iberoamericana, Vol. LXXIX, Núms. 244-245, Julio-Diciembre 2013, 989-999 ISSN 0034-9631 (Impreso) ISSN 2154-4794 (Electrónico) marginalidad con los propietarios. ${ }^{4}$

En La obra de mi vida vemos que la poesía de Heredia, desde la distancia, construye la tierra inalcanzable y añorada, una patria más soñada que vivida, siente "[...] el olor perdido de La Habana [...] con la intensidad dolorosa de la novela que ha sido mi vida, donde todo ocurrió en dosis exageradas [...]" (20). Siente la imposibilidad del regreso y augura el futuro: "[...] ¿Sería acaso el primero en sufrir la amarga experiencia, de sentir que aquella tierra sensual era insustituible en su corazón? [...]” (71). En los gestos del vate se funda la mitología que necesita la patria como espacio siempre añorado,desde y en el destierro, "[...] un país no escrito hasta entonces, y al cual dieron rostro y palabra, símbolos y mitología propios" (77).

El episodio más conflictivo de la biografia, la aceptación de su fracaso independentista, se inscribe en la infortunada carta al despótico Capitán General Miguel Tacón. Padura Fuentes justifica este acto en la necesidad de volver a la isla y a la familia. En la misiva consigna:

Es verdad que ha doce años la independencia de Cuba era el más ferviente de mis votos y que por conseguirla habría sacrificado gustoso toda mi sangre; pero las calamidades y miserias que estoy presenciando hace ocho años han modificado mucho mis opiniones y vería como un crimen cualquier tentativa de trasplantar a la feliz y opulenta Cuba los males que afligen al continente americano. (Heredia citado en Chacón y Calvo 110)

El escritor perseguido por la desgracia y la enfermedad y ansioso de abrazar a los suyos abjura de ideales independentistas. La ciudad letrada implacable lo condena, en especial Domingo del Monte. Si el padre, un liberal español escribió la historia de las violentas revoluciones de Venezuela, ${ }^{5}$ el hijo, después de haber participado en la organización del México independiente y presenciado la barbarie desatada por los caudillos duda de los beneficios de la revolución. Comparte la sensación de fracaso de muchos pensadores revolucionarios. El fundador de la cubanía literaria, repudiado y obligado a vivir y morir lejos e incomprendido. ${ }^{6}$ La historia se convierte en alegoría política del presente.

La segunda trama contenida en la novela narra la historia del manuscrito. Los avatares sufridos por los ciento dieciocho folios entregados por José de Jesús Heredia a la logia de los Hijos de Cuba de Matanzas en 1921 y su destrucción en 1838. La

${ }^{4}$ Como los grandes intelectuales del siglo xIx "[...] dudaron de la madurez espiritual de la isla para constituirse en una nación moderna occidental y equilibraron sus permanentes intervenciones con melancolía, zozobra y escepticismo" (Rojas, Tumbas 51).

Memorias sobre las revoluciones de Venezuela, José Francisco Heredia, 1895.

6 En El Centón Epistolario de Domingo del Monte se consigna la poderosa condena a la debilidad del amigo.

Revista Iberoamericana, Vol. LXXIX, Núms. 244-245, Julio-Diciembre 2013, 989-999 ISSN 0034-9631 (Impreso) ISSN 2154-4794 (Electrónico) 
memoria es sacrificada en aras del prestigio familiar. El aspirante a la presidencia de Cuba Domingo Vélez de la Riva los compra a un corrupto Ricardo Junco, temeroso de que la historia del hijo natural de Dolores Junco y José María Heredia manche a su poderosa familia. Sin embargo el lector se encuentra leyendo esa autobiografía destruida por el fuego, rescatada por la ficción.

En el presente de la escritura, el poeta e investigador literario, Fernando Terry, regresa a la isla siguiendo los pasos del libro extraviado. Está más interesado en encontra al traidor que provocó la muerte de su amigo Enrique, el dramaturgo que lo empujó al destierro. En esta zona se arma una ficción de autor, que apela a la reconstrucción de "la familia", el grupo de poetas, los Socarrones, que simbolizan distintos destinos: el combatiente en Angola, el perseguido homosexual, ${ }^{7}$ el literato triunfador, el poeta frustrado.

La fraternidad de origen ha sufrido la devastadora experiencia de los setenta, que arrasa con la edad dorada revolucionaria. La ficción de autor se resuelve en un doble plano, de afiliación vertical, con Heredia y de afiliación horizontal con los Socarrones. La única salida es la reconstrucción de los lazos y la aceptación de la contingencia histórica. Sólo se puede convivir con las ruinas del pasado, si se mantienen separadas poesía y política: "[...] Porque lo que tiene jodida a la literatura cubana es el delirio de la política" (163).

En las ficciones se esconde la historia oculta de la literatura cubana, encerrada en misteriosas bibliotecas. El escritor y la política corren el riesgo de colisionar. S el viaje de Heredia acaba con el destierro y la muerte ante la incomprensión de sus contemporáneos, el viaje de Terry concluye con la reconciliación, sin demasiada revisión crítica, de un pasado que se vive como fatalidad. Unica posibilidad de reparar el campo y el archivo literario. Todos los personajes resultan víctimas de una trama inmanejable. Fernando alcanza

La certeza de que todos ellos han sido personajes construidos, manipulados en función de un argumento moldeado por designios ajenos, encerrados en los márgenes de un tiempo demasiado preciso y un espacio inconmovible, tan parecido a una hoja de papel, le revela la tragedia irreparable que los atenaza: no han sido más que marionetas guiadas por voluntades superiores [...]. (341-342)

La figura de Enrique tiene rasgos de la tragedia de Virgilio Piñera. En Máscaras Leonardo Padura insiste sobre la figura de Piñeira y profundiza sobre el tema de la homosexualidad y la política cultural cubana. ISSN 0034-9631 (Impreso) Vol. LXXIX, Núms. 244-245, Julio-Diciembre 2013, 989-999 ISSN 2154-4794 (Electrónico)
LOS NARRADORES Y EL CRIMEN

En Adiós Hemingway, ${ }^{8}$ ficción neopolicial, el protagonista Mario Conde, detective retirado y aspirante a escritor, es una ficción de autor con múltiples elementos autobiográficos. Al desencantado y cínico ex policía le toca resolver la historia de un antiguo y misterioso cadáver descubierto en Finca Vigía, la propiedad de Ernes Hemingway convertida en museo. Padura Fuentes insiste en la condición novelesca del texto:

[...] De esta manera, el Hemingway de esta obra es, por supuesto, un Hemingway de ficción, pues la historia en que se ve envuelto es sólo producto de mi imaginación, y en cuya escritura practico incluso la licencia poética y posmoderna de citar algunos pasajes de sus obras y entrevistas para construir la larga noche del 2 al 3 de octubre de 1958. (12)

La reescritura del policial es una de las consecuencias del periodo especial, una inversión radical del modelo favorecido por las políticas estatales. ${ }^{9}$ El antihéroe fracasado extrema las figuras del policial negro y arrastra la historia de su tiempo. El espacio permite debatir las posibilidades de la justicia y de la ley. El discurso metaliterario plantea una reflexión sobre la literatura y la construcción del mito del escritor. El enigma tiene menos importancia que la revisión de la mitología de Hemingway en diálogo con el lector/ autor Mario Conde.

La trama se arma en dos tiempos, el presente de la investigación policiaca y el pasado de los últimos años de Hemingway en la isla. Dos planos temporales heterogéneos ya que en ambos los protagonistas vuelven, constantemente a pasados personales, nostálgicas edades doradas. En el caso del detective los años previos al periodo soviético, en el de Hemingway, los años europeos. La rememoración está teñida por la decepción de la actualidad: la crisis personal precipitada por la vejez y la esterilidad del escritor norteamericano y la crisis del Estado revolucionario para el Conde. En un punto del

\footnotetext{
Las historias de vidas pueden ser historias de muertes como en el caso del proyecto editorial "Literatura o muerte" lanzado por el Grupo Norma. La serie, dedicada a la muerte de escritores míticos sigue el modelo de la novela de enigmas. Está compuesta por títulos como Adiós Hemingway de Leonardo Padura, El enfermo Moliére de Rubem Fonseca, Cinco tardes con Simenon de Julio Paredes, El corazón de Voltaire de Luis López Nieves. Con de Luis López Nieves. Con agudeza, Rosa Pellicer señala el retorno del modelo policial inglés, donde enigma predomina sobre la acción

Sánchez plantea que el policial de fin de siglo se presenta como un ajuste de cuentas con el género, se juega con sus posibilidades, se apela a la seducción de los códigos compartidos con el lector para luego "decepcionarlo" con verdades imposibles de revelar, crímenes cometidos por el Estado, justicias que no se cumplen
}

Revista Iberoamericana, Vol. LXXIX, Núms. 244-245, Julio-Diciembre 2013, 989-999 ISSN 0034-9631 (Impreso) ISSN 2154-4794 (Electrónico) 
pasado las historias de los escritores se cruzan: la despedida de Cuba del norteamericano Hemingway. ${ }^{10}$

La memoria es un tópico constante en las dos historias cuyos paralelismos apelan a desdoblamientos y distancias. Ambas figuras mantienen una intensa relación con el paisaje, en especial con la ciudad y el mar. El Conde "[...] había hecho del mar, de sus efluvios y rumores, la escenografía perfecta para su espíritu y para su empecinada memoria [...]" (16). Para Hemingway, uno de los responsables de la Cuba exótica y dionisiaca, La Habana es "[...] una ciudad inabarcable y profunda, empeñada en vivir de espaldas al mar, y de la cual él sólo conocía algunos jirones [...] sabía lo indispensable de su dolor y de su vanidad palpitantes" (86).

Las historias familiares se arman en paralelo: Hemingway hereda de su abuelo el amor por las armas; el Conde recibe el tesoro de las historias de Rufino el Conde, el gallero. El nudo está en la despedida del niño y el viejo en el muelle. Mario, de la mano del abuelo, queda fascinado por la figura del norteamericano - "aquel hombre que hedía a mar, pescado y sudor" (7)- que, en 1960, se despide del Caribe, que inmortalizó en las novelas. El ex policía comprende, desde el presente, la totalidad de la escena. En medio de dos tiempos la relación transita desde la fascinación al odio. Como el río de Hemingway, el alma del Conde posee dos corazones. Repudia la profusa mitología de gran padre blanco, violento y machista, inventada, en gran medida, por las acciones y la vida del novelista. El mito de autor le parece una "[...] sabia escenografía calculada en vida para cuando llegara la muerte" (27).

Un mito aprovechado, cultural y materialmente, por el gobierno revolucionario, ${ }^{11}$ transformado en objetos turísticos: El Papa doble, la Marina Hemingway, un torneo de pesca, el museo, el Floridita, La Bodeguita del Medio. Hemingway, jefe de una iglesia laica cuyos primeros creyentes, los pescadores, no saben escribir. Los empleados de la finca, "hijos" / sirvientes son parte de un mundo natural y bárbaro. ${ }^{12}$ Lo retratan como un papá extranjero rudo casi grosero, generoso en dinero y gestos. El afecto suscitado en los pescadores de Cojimar "es una de las pocas verdades de su mito" (28)

${ }^{10}$ Otro detalle en el que se insiste en el desdoblamiento es la asociación de Hemingway a su perro Black Dog, un fino dogo negro de raza. Mientras que Mario Conde adopta a un perro callejero al que llama Basura.

${ }_{11}$ " [...] Sobre Hemingway - presencia diaria de Castro, quien posee en su despacho una foto junto a un enorme pez espada, con el siguiente autógrafo: "al doctor Fidel Castro, que clave uno como éste en el pozo de Cojímar. Con la amistad de Ernest Hemingway-" dice haber leído Por quien doblan las campana unas cuatro veces y haber aprovechado, durante la insurrección contra Batista, las descripciones de "[ [..] la lucha en la retaguardia de un ejército convencional [...]" El escritor norteamericano aparece como una figura que une lo militar con lo literario (Rojas, El estante 186).

12 Raúl le profesa una "fidelidad perruna"; Calixto contrabandista asesinó a un hombre; Toribio el Tuzao, le organiza las peleas de gallo y Ruperto el patrón del Pilar, lo acompaña en sus excursiones de pesca.

Revista Iberoamericana, Vol. LXXIX, Núms. 244-245, Julio-Diciembre 2013, 989-999 ISSN 0034-9631 (Impreso) ISSN 2154-4794 (Electrónico)
Si la figura de Hemingway combina sexismo, violencia y escritura, el Conde, atraído por el mundo del delito y acaba persiguiendo la violencia que repudia. El texto alterna las preocupaciones éticas y literarias. El escritor norteamericano se afana en libros interminables, mientras pierde memoria y virilidad. El viejo patriarca se apoya en rituales y glorias pasadas, y descubre "[...] una terrible evidencia, conocida, pero en la cual trataba de no pensar: si no podía correr aventuras ni recordar, ¿de qué vas a escribir, muchacho?" (16). Sólo resta el recuerdo de mujeres y aventuras.La casa museo, custodiada por una logia particular, los hemigwaynos cubanos, es un santuario que conserva gestos vacíos. En las paredes coexisten la literatura y la violencia, los libros y los fusiles.

Sus biógrafos y los críticos siempre insistían en destacar de su vida el gusto por el peligro, la guerra, las situaciones extremas, la aventura, en fin. Unos lo consideraban un hombre de acción devenido escritor, otros un payaso en busca de escenarios exóticos o peligrosos capaces de añadirle resonancia a lo que el artista escribía. Pero todos habían contribuido a mitificar, desde el elogio o desde la crítica, una biografía que, coincidían en esto, él mismo se había fabricado con sus acciones por medio mundo. (38)

Mario Conde, aferrado a su ciudad, devastada y tumultuosa hace de la amistad masculina un culto. La impotencia se cierne sobre la vida de los amigos/hermanos: el Flaco paralizado desde Angola, el Conde solitario, Andrés exiliado. El regreso a Finca Vigía supone la rememoración de los tiempos fraternales en los que las novelas del escritor "[...] fueron el modelo ideal de lo que podía ser la literatura y de lo que debía ser un hombre con una vida hecha por y para esa literatura" (40). Mario Conde, lector y escritor se resiste a quedar atrapado en el mito de Hemingway. Conoce sus traiciones a los anarquistas en la guerra civil española y su incomprensión de la realidad cubana:

[...] entendió que más de veinte años conviviendo con los cubanos no bastaron para que el artista comprendiera un carajo de la isla; cuando asimiló la dolorosa verdad de que aquel escritor genial era también un hombre despreciable, capaz de traicionar a cada uno de los que lo ayudaron [...]. (49)

La verdad se le escapa ya que no puede aseverar que Hemingway sea el asesino, aunque su pose sea mentirosa. ${ }^{13}$ El detective escritor recoge huellas del crimen en las narraciones y los libros de las bibliotecas cubanas. El cuerpo misterioso bajo el árbol es tan enigmático como el suicidio del escritor. No deja de admirar al extranjero que jugó a ser cubano y construyó una geografía indeleble a la isla y de los hombres del mar.

${ }_{13}$ Castro se proyecta públicamente, dentro y fuera de la isla, como un lector obsesivo, cuyos autores de cabecera son Ernest Hemingway y Gabriel García Márquez.

Revista Iberoamericana, Vol. LXXIX, Núms. 244-245, Julio-Diciembre 2013, 989-999 \begin{tabular}{ll}
\hline \hline ISSN 0034-9631 (Impreso) & ISSN 2154-4794 (Electrónico)
\end{tabular} 
Aunque repudie al que declaró que era un cubano sato y decidió entregar la medalla del Premio Nobel a la Virgen de la Caridad del Cobre, Patrona de Cuba. Una medalla "[...] que tanto le debía a unos hombres simples pero capaces de regalarle la historia de un pescador que llevaba ochenta y cuatro días luchando en la corriente del golfo sin capturar un pez, porque estaba definitiva y rematadamente salao" (111).

En Hemingway literatura y vida se confunden. El Conde sabe que la literatura no es la vida, aunque su vida sólo encuentra consuelo en la literatura. La identidad de Hemingway está forjada en el espectáculo. El crimen desnuda al hombre viejo atrapado en la trampa del FBI. El final es ambiguo, la segunda bala puede convertirlo en asesino El ex policía consigue que se cierre el caso y que no se manche al escritor. Un gesto que perdona la memoria.

El Conde, un buen policía, "[...] Pero ahora, ya lo sabía, era un cabrón detective privado en un país sin detectives ni privados [...]" (101), se reencuentra con Hemingway un buen escritor, a pesar de su amor por la violencia. La Habana de hoy es una dolorosa parodia de La Habana de Hemingway. La fiesta se repite, aunque la revolución haya intentado terminarla. Mario Conde/Leonardo Padura Fuentes se pregunta: "¿Hacia dónde vamos, adonde coño hemos llegado [...]? Aquella realidad devastadora que ahora veía adormecida por varios años, o fermentada en la oscuridad, entraba en erupción y sus nubes de humo enviaban señales de alarma" (104-105).

El mundo sensual y hedonista de las novelas de Hemingway, consolidó a La Habana como fantasía de la imaginación occidental en los años previos a la revolución. La Habana fantasía erótica de Occidente ha sido reemplazada por La Habana utopía tropical del comunismo. Hemingway es el otro extranjero que enfrenta a Conde con su propia imagen y, al mismo tiempo, el mito cuya destrucción le permite arrojar al mar los emblemas del escritor estrella, renunciar al mito para quedarse con la amistad y la literatura.

Rafael Rojas afirma que en Cuba la cultura urbana en la década de los noventa experimenta todos los síntomas del quiebre del canon nacional. En un horizonte marcado por la diseminación, Rojas distingue tres políticas de la escritura en la narrativa cubana: la del cuerpo, la de la cifra y la del sujeto. La novela de mi vida puede inscribirse dentro de la política de la cifra, la segunda se centra más en el sujeto. Ambas plantean la reflexión sobre el archivo literario. La ficción de autor reconoce una relación con dos mitos distintos, el del cubano arrojado de la patria y el del extranjero acogido en la isla En ambos casos el escritor interviene en la construcción de una genealogía literaria, donde entre el Mismo y el Otro, arma su propia fábula de identidad.

\section{BIBLIOGRAFÍA}

Amar Sánchez,Ana María.Juegos de seducción ytraición. Rosario: Beatriz Viterbo, 2000. Barthes, Roland. Mitologías. Barcelona: Siglo XXI, 1981.

Chacón y Calvo, José María. Estudios Heredianos. La Habana: Editorial Trópico, 1939.

Fuentes, Norberto. Hemingway en Cuba. Cuba: Editorial Letras Cubanas, 1984.

González Echevarría, Roberto. "Reflexiones sobre Espejo de paciencia de Silvestre de Balboa”. Nueva Revista de Filología Hispánica 35/2 (1987): 571-590.

González del Valle, Francisco. Cronología Herediana (1803-1839). La Habana: Secretaría de Educación-Dirección de Cultura, 1938.

Heredia, José María. Niágara yotros textos (Poesía y Prosa selectas). Caracas: Biblioteca Ayacucho, 1990.

"Ensayo sobre la novela". La Miscelánea (marzo-abril 1832). Recogidas en José María Chacón y Calvo.

Poesías Líricas. París: Garnier Hermanos, 1892.

Mitjans, Aurelio. Historia de la literatura cubana. Madrid: Editorial-América, 1918.

Padura Fuentes, Leonardo. La novela de mi vida. Barcelona: Tusquets, 2002. José María Heredia: la patria y la vida. La Habana: Ediciones Unión, 2003. Adiós Hemingway. Bogotá: Editorial Norma, 2003.

"Crónica de fin de siglo". Cuba: Voces para cerrar un siglo (I). Bipolaridad de la cultura cubana. René Vázquez Díaz, comp. Suecia: Centro Internacional Olof Palme, 1999.

Premat, Julio. Héroes sin atributos: figuras de autor en la literatura argentina. Buenos Aires: Fondo de Cultura Económica, 2009.

Rojas, Rafael. Tumbas sin sosiego: revolución, disidencia y exilio del intelectual cubano. Barcelona: Anagrama, 2006.

Motivos de Anteo: patria y nación en la historia intelectual de Cuba. Madrid: Editorial Colibrí, 2008

El estante vacio. Literatura y política en Cuba. Barcelona: Anagrama, 2009.

Said, Edward. El mundo, el texto y el crítico. Buenos Aires: Debate, 2004.
Revista Iberoamericana, Vol. LXXIX, Núms. 244-245, Julio-Diciembre 2013, 989-999 ISSN 0034-9631 (Impreso)
Revista Iberoamericana, Vol. LXXIX, Núms. 244-245, Julio-Diciembre 2013, 989-999 ISSN 0034-9631 (Impreso) ISSN 2154-4794 (Electrónico) 
